\title{
RELEASE OF SEVERE POST BURN CONTRACTURE OF NECK UNDER LOCAL ANAESTHESIA BEFORE INTUBATION IN CASE OF DIFFICULT INTUBATION
}

Ramesha K.T1 ${ }^{1}$ Neelammaㄹ, Shankarappa $\mathrm{M}^{3}$

\section{HOW TO CITE THIS ARTICLE:}

Ramesha KT, Neelamma, Shankarappa M. "Release of severe post burn contracture of neck under local anaesthesia before intubation in case of difficult intubation". Journal of Evolution of Medical and Dental Sciences 2013; Vol2, Issue 39, September 30; Page: 7530-7532.

ABSTRACT: INTRODUCTION: Severe post burn scar contracture of neck causes insufficient neck extension, resulting in difficult intubation that can be life-threatening1, 2. It's very challenging to the anesthesiologist to manage airway so in such patients post burn contracture scar should be released before other procedures are performed, in order to ensure easy orotracheal intubation.

KEY WORDS: Post burn contracture neck, intubation, contracture release, local anaesthesia, airway.

AIM OF THIS STUDY: To show our experience with early surgical neck contracture release of patients with severe post burn contracture (PBC) of the neck under local anaesthesia to facilitate intubation and to determine effectiveness/safety of this technique.

MATERIALS AND METHODS: Prospective study done in plastic, burns and reconstructive surgery department Victoria hospital BMC \& RI Bangalore from august $1^{\text {st }} 2011$ to July 30 2013 . For all patients of post burn neck contracture with difficult intubation early neck contracture released under local anaesthesia (2\% lignocaine 30cc with $30 \mathrm{cc}$ normal saline and 1:200000 adrenaline) to facilitate easy orotracheal intubation then further complete release and grafting continued under general anaesthesia. Stepwise early contracture release under local anaesthesia showed in figure 2 .
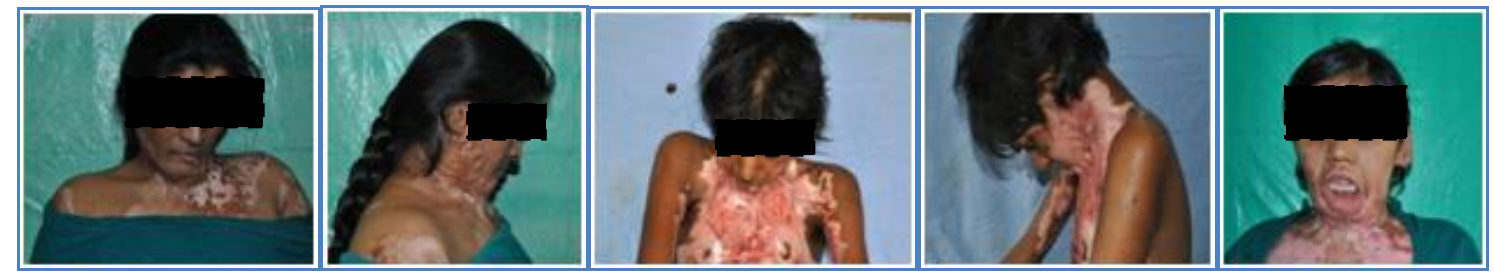

Fig 1: post burn neck contracture
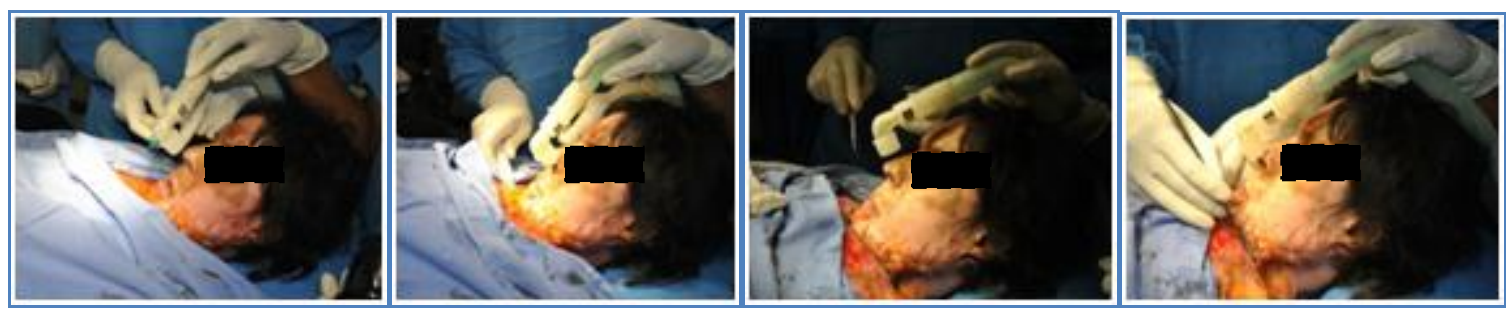

Fig 2: A and B - local anaesthesia infiltration, C- marking for release, D-skin incision 


\section{ORIGINAL ARTICLE}
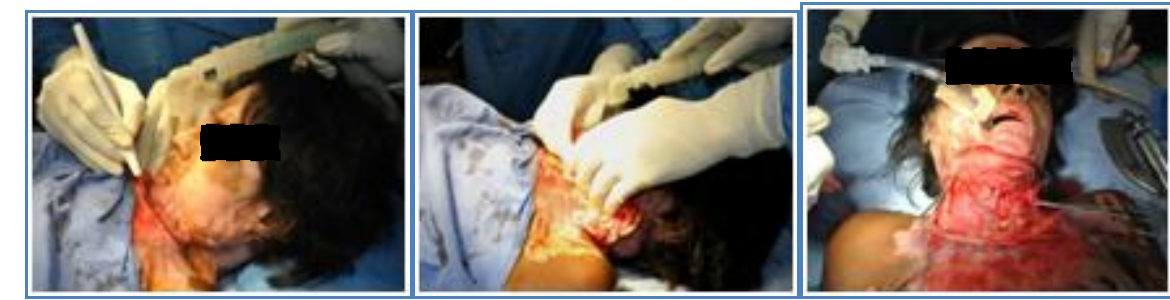

E-release with cautery, F-manual contracture release, G-after

RESULTS: Total 25 patients (17 female and 8 male) of post burn contracture neck with difficult intubation were operated with mentioned technique and among 25patients 2 patients associated with microstomia and was released under local anaesthesia to facilitate safe orotracheal intubation. Total operative time ranged from 70 to 90 minutes. None of the 25 patients treated with this operative technique showed any intraoperative complications and no immediate post op complications. 4 patients developed minor wound infection but no graft loss.

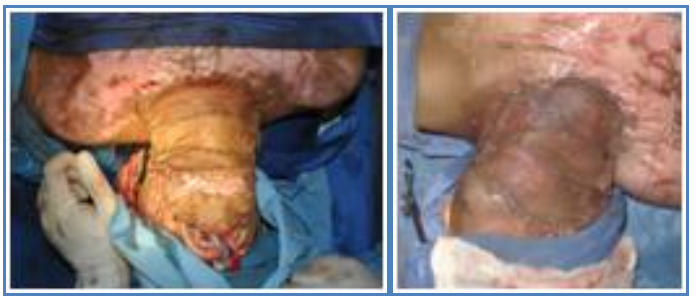

Fig 3: Immediate post-op photos

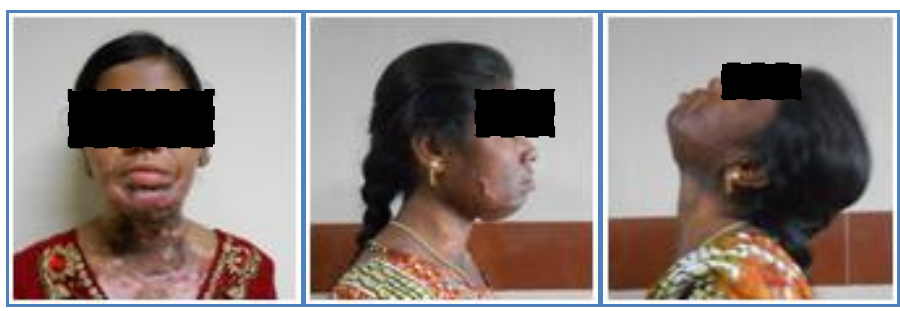

Fig 4: delayed post-op photos

DISCUSSION: Contracture release of the neck prior to intubation was first described in 1964 by Tanzer et $\mathrm{al}^{3}$. They suggested a release of the inferior half of the neck under local anaesthesia when difficulties are anticipated. Further release would follow successful intubation ${ }^{3}$. Restricted mouth opening, decreased oropharyngeal space, limited atlanto-occipital joint extension and heavily fibrosed scar in the neck lead to a difficult airway 4 . Use of standard laryngoscopy was not possible in severe post burn neck contracture due to non-alignment of oral/pharyngeal axis and direct laryngoscopy also hampered by the presence of limited cervical extension 5 andbronchoscopy itself can be difficult if the anatomy of the airway is distorted owing to soft tissue contracture, especially when repeated attempts to intubate have resulted in the presence of blood and secretions in the oropharynx. . Other methods include use of fibre-optic bronchoscope and laryngeal mask but these equipments are expensive and may not be available in most places ${ }^{6}$.Retrograde intubation is not 
possible because of presence of scar in the anterior aspect of neck. Blind nasal intubation may be successful, but the positioning of the head and neck may be severely limited and repeated attempts present the risk of nasal bleeding, which may further endanger the airway ${ }^{7}$.

CONCLUSION: Early release of post burn contracture of neck under local anaesthesia before intubation in case of difficult intubation is a safe, simple and effective method.

\section{REFERENCES:}

1. Shiby Ninan, Gupta AK Ramkumar G. A technique in positioning the neck during menosternal contracture release. Burns 2003; 29:13-4.

2. Nath S, Erzingatsian K, Simond S. Management of post burn contracture of the neck. Burns 1994; 20:438-41.

3. Tanzer RC. Burn contracture of the neck. Plast Reconstr Surg 1964; 33: 207-12.

4. Gupta P, Talwar V, Vermas, Mahajan S, Gogia AR. Modified mouth prop for orotracheal fibreoptic intubation. J Anaesthesiol cl pharmacol 2006;22:65-8

5. Kreulen M, Mackie D, Kries R, Groenvelt F, Surgical release for intubation purposes in postburn contracture of the neck. Burns 1996;22:310-2

6. Afilalo M, Guttman A, Stern E, Lioyd J, Colacone A, Tselios C et al, Fibreoptic intubation in the emergency department: A case series. J Emergency medicine 1993;11:387-91

7. S.M. Al-Zacko, D.A. Al-Kazzaz. Annals of Burns and Fire Disasters. 2009 December 31; 22(4): 196-199.

\section{AUTHORS:}

1. Ramesha K.T.

2. Neelamma

3. Shankarappa M.

\section{PARTICULARS OF CONTRIBUTORS:}

1. Associate Professor, Department of Plastic, Burns and Reconstructive Surgery, Bangalore Medical College and Research Institute, Bangalore.

2. Resident, Department of Plastic, Burns and Reconstructive Surgery, Bangalore Medical College and Research Institute, Bangalore.

3. Professor and HOD, Department of Plastic, Burns and Reconstructive Surgery, Bangalore Medical College and Research Institute, Bangalore.

\section{NAME ADDRESS EMAIL ID OF THE CORRESPONDING AUTHOR:}

Dr. Ramesh K.T., Associate Professor, Plastic Surgery Department, Victoria Hospital, Bangalore - 560002 .

Email-rameshktr@yahoo.com

Date of Submission: 16/09/2013. Date of Peer Review: 17/09/2013. Date of Acceptance: 23/09/2013. Date of Publishing: 27/09/2013. 